\title{
Introduction to the Special Issue - Emerging markets: exploring the diversity of theories, practices, and applications
}

About the guest editors

Keith Perks is a Reader in Marketing at the University of Brighton, Brighton Business School. His research interests are in the area of international management strategy, international entrepreneurship, cross cultural management, and emerging markets.

Dr. Phani Tej Adidam is the Executive Education Professor, and Director of International Initiatives at the University of Nebraska at Omaha. His research is in the area of marketing strategy, decision confidence, competitive intelligence, and sales management.

The articles in this special issue of the International Journal of Emerging Markets are a selection of the best papers from the International Management Research Academy (IMRA; www.imraweb.org) 2012 conference held in London in May 2012. This conference was dedicated to research carried out by scholars located in emerging markets from regions across the world. The papers represent a cross-section of studies from three regions: Eastern Europe, Africa and Asia. The theme of the conference was: Emerging Markets and the New Dynamics of Management. Emerging markets are diverse in terms of their political economies, population, legal infrastructure, technological advancements and cultures, yet they tend to be grouped together by business and academic commentators and researchers. However, there are significant differences and divergences in emerging markets between the rich, emerging middle class and the poor with the latter making up the majority of the population. Suffering from the problems of inadequate infrastructures several of these countries are the source of "resourceful" innovators and entrepreneurs. Innovative technologies such as mobile telephony and renewable energy sources are being adopted rapidly. This diversity and specific characteristics we believe need to be better understood particularly in terms of how organizations, managers, entrepreneurs are practicing management and how scholars based in these countries are developing new knowledge, theory and reporting on management practices.

In the nineteenth and twentieth centuries the countries of the occident were considered to be the sources of the foundations and development of management knowledge, theory and practice related to the industrialization, economic growth and dominance of world trade. In the latter part of the twentieth century the economic growth and power of the Japanese economy shifted the balance of economic power towards Asia. In the last two decades BRIC countries (Brazil, Russia, India and China) and CIVETS (Colombia, Indonesia, Vietnam, Egypt, Turkey and South Africa) among many other emerging markets now account for around 50 per cent of revenues for global corporations such as Proctor \& Gamble and Unilever. Whilst the shift in economic hegemony has been recognized there remains a view that western management ideas, theories and practices still dominate with less debate and research into the management ideas and practices emanating from emerging markets. 
The first paper in this special issue by Yair Aharoni is a reflection on the developments in international business research from pioneering work of scholars in the field in the context of a world divided into rich market economies, communist countries and a third world of undeveloped countries to the current state of the world economy whereby emerging market multinationals enterprises (EMMEs) from rapidly developing economies represent a significant change in the balance of economic and political power. In this new world order, EMMEs in some knowledge-based industries cooperate with MNEs from developed countries as equal technology partners and are no longer searching for technology transfers. Aharoni calls for a "dynamic IB contingency theory" in International Business research to challenge the boundaries of existing theories grounded in the past and "be able to conceive a regime, a strategy or a way of thinking that is different than the status quo and of the rules of the game to which one is accustomed in one's own country". This paper sets the scene for the following four papers written by scholars from the "other" emerging market perspective, based on the contingencies of regions and countries in the world providing insights into business, management and marketing theories and practices in novel under-researched contexts. The diversity of topics of the papers range from: marketing to the emerging middle class and the challenge of logistics in Africa; strategic management styles in Central and Eastern European markets and finally; high-technology institutional entrepreneurs in environmental and sustainable industry sectors in China.

The paper by Tendai Chikweche and Richard Fletcher is timely in relation to the increasing amount of attention given to Africa and the emergence of middle class entrepreneurs creating a new business class and consumer segment. The research contributes to the lack of knowledge about the emerging "missing" middle class in Africa and in particular on the impact of social networks in the interaction between firms and consumers. The authors find that specific social networks and interactions surrounding social occasions and events, give valuable insights into the African emerging middle class market context.

Oguji Nnamdi and Richard Owusu's paper "Negligence of Africa as a source location: literature review and implications" reviews the literature on sourcing issues identifying only 40 articles in supply chain journals from 1980 to 2013 in the Sub-Saharan African context. The authors find that there is an under-representation of supply chain management literature about this region in comparison with other emerging markets such as Asia and developed markets. As this region is experiencing development and growth with increasing interest in the supply particularly of agricultural products from Africa then the authors argue that far more scholarly research on supply chain management theory and practice is needed.

The next paper "Strategy development processes in Central and Eastern Europe: a crossregional perspective" by Bernadette Koles and Kondrath Balakrishnan is a comparative study of the strategy development processes in a cross-regional context and examines the 
consistency in the strategy processes of organizations operating in the Central and Eastern Europe (CEE) compared with those in the west. The paper explores the strategy development process using multiple dimensions across several managerial levels. The study finds that despite the surface level similarities between western and CEE company strategy processes there are important differences. These differences are that CEE top managers place more emphasis on the importance of the chief executive; they carry out a more systematic evaluation of strategic options; and have a tendency to continually adjust the organization's strategy. Therefore, the authors argue it is important for MNCs executives entering different CEE countries to be aware of these particular societal level influences on the strategy development process in order to reduce the potential for problems.

The main purpose of the final paper by Xuanwei Cao, Yipeng Liu and Chunhui Cao "Institutional Entrepreneurs in opportunity formation and exploitation in strategic new industry: two cases of solar energy industry development in China" is to evaluate two contrasting case studies in the solar energy industry using the framework of institutional entrepreneurship and the importance this concept plays in opportunity formation and exploitation in strategic new industries. The two case studies are situated in the Grand Western Development and the Thousand Talents Programs in China. The authors find that there are varying and contrasting effects in stimulating institutional change and innovation. A top-down process of institutional innovation driven by local government may lead to a distortion of market opportunities. In contrast individual entrepreneurs with well-accumulated political capital and strong sense of responsibility could be a more effective strategy for incremental institutional change combining a bottom-up and top-down approach.

In conclusion, there is a clear need for academic associations, communities and organizations to engage in a robust dialogue about the global changes that are occurring and the effects they are having and will have on developed and emerging economies. Finally, we argue that there is a significant gap between academic knowledge, theory and practice which needs to be addressed by researchers from both developed and emerging economies. The IMRA 2012 conference was an attempt to address a lacunae in research and knowledge from scholars located in many developed and emerging countries and we believe that the articles in this special issue contributes towards the dialogue. 